\title{
A perspectiva decolonial da etnomatemática como movimento de resistência
}

\author{
Maria Cecilia Fantinato 1 \\ Universidade Federal Fluminense (UFF), Faculdade de Educação, Niterói, RJ, Brasil
}

Adriano Vargas Freitas ${ }^{2}$

Universidade Federal Fluminense (UFF), Faculdade de Educação, Niterói, RJ, Brasil

\begin{abstract}
Resumo
Este artigo se baseia nas seguintes ideias centrais: (a) historicamente, as produções em etnomatemática têm apresentado resultados de pesquisa sobre conhecimentos que podem ser entendidos como matemática; (b) uma das potências da etnomatemática é a de romper com uma visão arraigada de matemática única, idealizada, ahistórica, elitista, eurocêntrica, aproximando-se, portanto, de uma proposta decolonial, ao reconhecer e valorizar os muitos saberes presentes nas práticas sociais; (c) o processo histórico de colonização implicou em conquistas territoriais e na destruição das raízes culturais dos povos colonizados, como forma de eliminar sua historicidade, e (d) A crescente participação de pesquisadores provenientes dos movimentos sociais nesta área pode contribuir para evitar tais contradições. Com base nestas perspectivas, na primeira parte destacamos que a etnomatemática, em sua dimensão política, pode auxiliar nas reflexões a respeito de processos de decolonialidade, assim como no reconhecimento das raízes culturais dos indivíduos. Na segunda parte apresentamos breves metatextos dos artigos que compõem o dossiê "Etnomatemática: perspectiva decolonial e movimentos de resistência", como forma de apresentar ao leitor as recentes contribuições de pesquisadores brasileiros e estrangeiros, e estimular o debate sobre o tema.
\end{abstract}

Palavras chave: Etnomatemática; Decolonialidade; Educação Matemática.

\section{The decolonial perspective of ethnomathematics as a resistance movement}

\begin{abstract}
This article is based on the following core ideas: (a) historically, productions in ethnomathematics present research results on knowledge that can be understood as mathematics. (b) one of the powers of ethnomathematics is to break with the common idea of unique, idealized mathematics, distant from

Submetido em: 26/06/2021

Aceito em: 18/08/2021

Publicado em: 01/09/2021

1 Doutora em Educação pela USP. Professora do Programa de Pós-Graduação em Educação da UFF. E-mail: mc fantinato@id.uff.br

2 Doutor em Educação Matemática pela PUC-SP. Professor do Programa de Pós-Graduação em Educação da UFF. E-mail: adrianovargas@id.uff.br
\end{abstract}


the history of humanity, elitist, Eurocentric. Ethnomathematics approaches a decolonial proposal by recognizing and valuing the many knowledges present in social practices. (c) the historical process of colonization implied territorial conquests and the destruction of the cultural roots of colonized peoples. This is a way to eliminate the history of these peoples. (d) The growing participation of researchers from social movements can help to avoid such contradictions. Based on these perspectives, in the first part of this article we emphasize that ethnomathematics, in its political dimension, can help in reflections on decolonization processes, as well as in the recognition of the cultural roots of individuals. In the second part, we present brief metatexts of the articles that make up the dossier "Ethnomathematics: decolonial perspective and resistance movements", as a way of introducing the reader to recent contributions by Brazilian and foreign researchers, and stimulating debate on the subject.

Key words: Ethnomathematics; Decoloniality; Mathematics Education.

\section{La perspectiva descolonial de las etnomatemáticas como movimiento de resistência}

\section{Resumem}

Este artículo se basa en las siguientes ideas centrales: (a) históricamente, las producciones en etnomatemática presentan resultados de investigación sobre conocimientos que pueden entenderse como matemáticas. (b) uno de los poderes de las etnomatemáticas es romper con la idea común de las matemáticas únicas e idealizadas, distante de la historia de la humanidad, elitista, eurocéntrico. La etnomatemática aborda una propuesta descolonial reconociendo y valorando los múltiples saberes presentes en las prácticas sociales. (c) el proceso histórico de colonización implicó conquistas territoriales y la destrucción de las raíces culturales de los pueblos colonizados. Esta es una forma de eliminar la historia de estos pueblos. (d) La creciente participación de investigadores de movimientos sociales puede ayudar a evitar tales contradicciones. Con base en estas perspectivas, en la primera parte de este artículo enfatizamos que la etnomatemática, en su dimensión política, puede ayudar en las reflexiones sobre los procesos de descolonización, así como en el reconocimiento de las raíces culturales de los individuos. En la segunda, presentamos breves metatextos de los artículos que componen el dossier "Etnomatemática: perspectiva descolonial y movimientos de resistencia", como una forma de acercar al lector a los aportes recientes de investigadores brasileños y extranjeros, y estimular el debate sobre el tema.

Palabras clave: Etnomatemática; Descolonialidad; Educación Matemática.

\section{Etnomatemática e decolonialidade}

Quais são as aproximações entre a decolonialidade e a etnomatemática? Como as pesquisas recentes têm respondido a este debate cada vez mais necessário? Em outras palavras, em que medida a etnomatemática tem representado um legítimo movimento de resistência na educação matemática, em prol da visibilidade e da legitimidade de saberes do Sul? Esta temática tem sido aprofundada, de 
diferentes formas, por alguns grupos de pesquisa do Brasil $^{3}$ e entre eles, pelo Grupo de Etnomatemática da UFF (GETUFF), coordenado pelos autores deste artigo. Esses debates têm sido travados nas reuniões do grupo, pela participação em eventos realizados de modo remoto ${ }^{4}$ e também têm gerado diversas publicações (FANTINATO; FREITAS; DIAS, 2020) 5 .

O sentido dado aqui para Sul não corresponde necessariamente ao Sul geográfico, muito embora possa haver uma sobreposição parcial entre ambos (Santos, 2019). O termo Sul tem sido também utilizado para substituir outras expressões, como países de Terceiro Mundo ou países em desenvolvimento, que caíram em desuso devido a sua carga preconceituosa (AKKARI; DASEN, 2004). Outra expressão próxima, mas não análoga, é o termo Sulear ${ }^{6}$, que o físico e antropólogo Marcio D’Olne Campos, formulou e tem teorizado a respeito (CAMPOS, 1999).

Alguns autores do movimento decolonial (DUSSEL, 2000; CORONIL, 2000) problematizam a ideia naturalizada, de que as ciências ocidentais são reconhecidas como tendo origem européia, contextualizando historicamente a formação da Europa e indicando a origem asiática e africana da chamada ciência ocidental. No coração da formação da matemática como disciplina ocidental, encontra-se uma história complexa de trocas. Neste sentido, as diferentes perspectivas teóricas decoloniais $^{7}$ (LANDER, 2000; SANTOS, 2019; CAMPOS, 1999) têm em comum suas críticas à permanência de formas de ser e saber entre pessoas em situação subordinada, que perpetuam a hegemonia do pensamento eurocêntrico ocidental.

A chamada virada decolonial não se refere a uma única escola teórica, mas aponta para uma família de posições diversas que compartilham uma visão da colonialidade como um problema fundamental na era moderna, e também a decolonialidade como sendo uma tarefa necessária que permanece inacabada (MALDONADO-TORRES, 2011). A independência política das colônias europeias em diferentes continentes não significou o fim do colonialismo (SANTOS, 2019), pois as estruturas construídas por 400 anos ou mais não desaparecem rapidamente. Segundo Grosfoguel (2009), deixamos um período de "colonialismo global" para entrar em uma era de "colonialidade global". O processo histórico de colonização implicava em conquistas territoriais e na destruição das raízes culturais dos povos colonizados, como forma de eliminar sua historicidade. Nas antigas

3 Podemos citar os grupos: Laboratório de Práticas Matemáticas do Ensino (LaPraME) da UFRJ, e o InSURgir Educação Apesar De, da UFMG.

${ }^{4}$ A palestra "Etnomatemática, Etnociência e Decolonialidade", organizada pelo Grupo de Etnomatemática da UFF e o Programa Dá Licença, aconteceu no dia 02 de outubro de 2020. Ela foi coordenada pela Profa. Maria Cecilia Fantinato, e contou com os Professores Ubiratan D'Ambrosio e Marcio D'Olne Campos. Link para acesso: https://www.youtube.com/watch?v=hXqvPWuecMs

${ }^{5} \mathrm{O}$ presente tópico apresenta recortes atualizados de artigo expandido na referida publicação.

6 Maiores informações na página do pesquisador https://www.sulear.com.br/ Acesso em 16.08.20

${ }^{7}$ Embora reconheçamos que alguns autores utilizam outras expressões, como o descolonizar, por Boaventura de Sousa Santos, ou Sulear, de Marcio D'Olne Campos, optamos aqui por adotar o termo decolonialidade. 
colônias permanece, portanto, a colonialidade do poder (QUIJANO, 2000), sendo substituída por outras formas de colonialismo interno, como o racismo e a xenofobia. As relações coloniais de poder deixaram marcas profundas no entendimento geral do ser: "A colonialidade do ser torna-se concreta sob a forma de sujeitos liminares, que marcam, por assim dizer, o limite do ser, ou seja, aquele ponto no qual o ser destrói o sentido e a prova até o ponto da desumanização (MALDONADO-TORRES 2007, p.257).

Guardadas as suas especificidades, as ideias do movimento da decolonialidade, das epistemologias do Sul de Boaventura de Sousa Santos e da proposta Sulear de Marcio D’Olne Campos (1999), têm em comum a crítica à permanência de formas de ser e saber, entre os povos em situação de subalternidade, que perpetuam a hegemonia do pensamento ocidental, eurocêntrico. Essas perspectivas teóricas decoloniais apontam para movimentos de resistência oriundos dos movimentos sociais, a partir de outras lógicas e saberes.

Num sentido próximo, D’Ambrosio (2001) menciona que a etnomatemática, em sua dimensão política, "se encaixa na reflexão sobre a descolonização" e no reconhecimento das raízes culturais dos indivíduos. Deste modo, desde o início, a pesquisa em etnomatemática já estava associada, de certa forma, a um movimento de resistência, à perspectiva decolonial. Entretanto, tal processo também está sujeito a contradições. Por exemplo, se a investigação adota a matemática ocidental como legitimadora dos saberes dos grupos sociais, ou se assume uma perspectiva "extrativista" de investigação (SANTOS, 2019), corre o risco de reforçar a colonialidade do conhecimento (QUIJANO, 2005). Pesquisadores da área têm procurado lidar com essas contradições de diferentes formas. Uma delas, é pela crescente participação de pesquisadores provenientes dos movimentos sociais, em pesquisas em grande parte desenvolvidas com o que podemos designar de grupos subalternos.

Grupos subalternos são aqueles que sofrem algum tipo de subordinação aos grupos hegemônicos. O termo subalterno, proposto originalmente por Antonio Gramsci, é utilizado pelas ciências sociais para designar os setores marginalizados da sociedade e não se refere a uma categoria monolítica e indiferenciada, pois "o sujeito subalterno colonizado é irremediavelmente heterogêneo" (SPIVAK, 2010, p.57). "O termo deve ser resgatado, retomando o significado que Gramsci lhe atribui ao se referir ao "proletariado", ou seja, aquele cuja voz não pode ser ouvida" (ALMEIDA, 2010, p.12). Para a indiana Gayatri Spivak (2010), o termo subalterno descreve "as camadas mais baixas da sociedade constituídas pelos modos específicos de exclusão dos mercados, da representação política e legal, e da possibilidade de se tornarem membros plenos no estrato social dominante" (SPIVAK, citada por ALMEIDA, 2010, p.12). Os sujeitos subalternos estão invisibilizados, pela linha abissal (SANTOS, 2019), a zona de exclusão, de não-ser, experienciada pelo colonizado (FANON, 1968). 
Segundo Boaventura de Souza Santos, a linha abissal "marca a divisão radical entre formas de sociabilidade metropolitana e formas de sociabilidade colonial que caracterizou o mundo ocidental moderno desde o século XV" (SANTOS, 2019, p.42-43). Essa divisão cria dois mundos de dominação que se apresentam como incomensuráveis, o metropolitano - da equivalência e da reciprocidade entre "nós", que são como "nós", integralmente humanos, e o colonial - o mundo do "eles", relativamente aos quais é inimaginável qualquer equivalência ou reciprocidade, já que não são totalmente humanos, pois estão do outro lado da linha abissal.

Em entrevista por Donna Landry e Gerald MacLean (1996), Spivak lembra que o lado perverso do desenvolvimento do capitalismo tem sido o crescimento da variedade de grupos em situação de subalternidade e invisibilidade social. Apesar de também afetados pela globalização, entre esses grupos a possibilidade de mobilidade social é muito reduzida. Outro aspecto abordado por Spivak (2010) é a necessidade de um projeto de "desaprendizagem" por parte dos intelectuais, que se sentem no direito de falar pelos subalternos, como se de fato fossem os próprios. A autora desvela o lugar incômodo e a cumplicidade do intelectual que julga poder falar pelo outro e, por meio dele, construir um discurso de resistência. "Segundo Spivak, a tarefa do intelectual pós-colonial deve ser a de criar espaços por meio dos quais o sujeito subalterno possa falar para que, quando ele ou ela o faça, possa ser ouvido (a)" (ALMEIDA, 2010, p.14). Muitos pesquisadores em etnomatemática têm procurado exercer este papel de "intectual pós-colonial" a que se refere a autora.

Segundo Santos (2019), Spivak (2010) sinalizou veementemente para a tragédia das ciências críticas modernas, que cedeu à tentação de dar voz aos silêncios dos grupos subalternos:

O pressuposto ingênuo do investigador abissal é o de que a sua voz é transparente, que não se confunde com as vozes dominantes e que pode, portanto, ser "dada" aos dominados como se fosse deles [...] Dar voz é menos transparente do que afirma ser; pode ser (e muitas vezes foi) ou uma voz dominante traduzida num dialeto dominado ou uma voz dominada seletivamente traduzida num dialeto dominante. (SANTOS, 2019, p.256)

Com efeito, ao estudar grupos subordinados, a ciência moderna sempre se baseou em alguém de fora (outsider) produzindo ciência sobre alguém de dentro (insider), sendo este último concebido como um provável informante, mas não como um provedor de conhecimento (Santos,2019). Ao assumir uma postura legitimista (Costa, 2003), ao adotar a matemática acadêmica - "dialeto dominante" - na leitura e interpretação das falas do "outro" - "dialeto dominado", a etnomatemática corre esse risco a que se refere Boaventura Santos. Esta é uma das críticas que se pode fazer à modelagem, tomada como caminho para as aplicações da perspectiva etnomatemática ao contexto escolar. A crítica que este mesmo autor faz às metodologias extrativistas aplica-se também a algumas pesquisas em etnomatemática, quando o pesquisador assume o lugar do outro, fala - sozinho - pelo grupo subalterno. Neste sentido, Spivak alerta "para o perigo de se constituir o outro e o subalterno 
apenas como objeto de conhecimento por parte de intelectuais que almejam meramente falar pelo outro" (ALMEIDA, 2010, p.12-13).

Em contrapartida, a etnomatemática pode ser considerada como um "movimento decolonizador" (BERNALES ; POWELL, 2018), por valorizar o conhecimento matemático dos grupos em situações de subordinação. Um dos objetivos da etnomatemática é justamente questionar o mito eurocêntrico que influencia os currículos escolares, desafiando a idéia de que a matemática é uma disciplina neutra e que o conhecimento matemático transcende a cultura (POWELL; FRANKESNTEIN, 1997). Entretanto, a pesquisa em etnomatemática corre o risco de ser contraditória a esse objetivo, se o pesquisador não desistir de uma concepção platônica de matemática. Portanto, os etnomatemáticos devem questionar a ideia da matemática universal e ahistórica e abraçar a pluralização das noções de conhecimento, matemática, racionalidade, cognição e aprendizagem (CLARETO, 2009). Para respeitar este movimento, os pesquisadores etnomatemáticos deveriam procurar conhecer juntos com o outro, em vez de conhecer sobre o outro (SANTOS, 2019).

\section{Sobre os artigos do Dossiê}

Nesta segunda parte deste artigo apresentamos pequenos metatextos sobre cada um dos artigos e resenhas que compõe o dossiê "Etnomatemática: perspectiva decolonial e movimentos de resistência", como forma de apresentar ao leitor as recentes contribuições de pesquisadores brasileiros e estrangeiros, e estimular o debate sobre o tema.

O primeiro artigo deste dossiê apresenta um dos últimos registros do pensamento de Ubiratan D’Ambrosio. Claudio Fernandes da Costa conversou com este que é considerado como o principal teórico da etnomatemática. Nesta entrevista o autor, e outros componentes do Grupo de Etnomatemática da Universidade Federal Fluminense, propuseram a D’Ambrosio questões que envolvem o seu Programa Etnomatemática e as teorias da decolonialidade. Estas se apresentaram como instigantes meios para o entrevistado analisar e formular críticas contundentes às diferentes formas de dominação e de exclusão de conhecimentos. Assim, a entrevista nos apresenta a defesa de uma concepção histórica e dialética onde a vida, as culturas, o ser humano e suas relações sociais e com a natureza devem ocupar um lugar central. Além disso, problematiza pontos relacionados a nova Base Nacional Comum Curricular enquanto documento que visa a imposição de práticas curriculares, e destaca outros importantes temas, tais como a globalização, a tecnologia, e ensino remoto.

No artigo das autoras Carolina Tamayo e Jackeline Rodrigues Mendes, "Opção decolonial e modos outros de conhecer na Educação (Matemática)" são destacadas algumas questões para 
pensarmos os efeitos de assumirmos uma opção decolonial no campo da Educação Matemática, com destaque para a Etnomatemática, tais como: O que saber? Quais saberes? As autoras analisam a colonialidade do saber que tem gerado o processo radicalmente excludente de universalidade, além de classificações e hierarquizações de povos e suas experiências históricas, assim como a promoção da superioridade dos conhecimentos produzidos pela sociedade moderna. Analisam que a Etnomatemática pode ser um movimento de contra conduta no interior da Matemática e da Educação Matemática, por envolver o questionamento às narrativas de universalização do conhecimento matemático, assim como em relação à promoção de uma verdade única para dizer o que pode ser considerado como conhecimento, provocando assim, um movimento decolonial.

Marcio D’Olne Campos, em seu artigo intitulado “Saberes acadêmicos nas etnografias de saberes locais indisciplináveis: etno-matemáticas e outras etno- $x$ ", destaca momentos históricos que nos permitem compreender o movimento do evolucionismo social à diversidade cultural da moderna antropologia, nos conduzindo, em seguida, às discussões relacionadas a etnografia de saberes, técnicas e práticas, etno-x e etnomatemática. Destaca que captar o universo de significados de outra cultura vai exigir do pesquisador um esforço de captar os fenômenos a partir dos referenciais dessa própria cultura, das suas categorias nativas. Analisa em seguida o Programa Etnomatemática, destacando a existência concepções diferenciadas propondo sempre um debate crítico sobre a separação entre os saberes da academia e os saberes locais de populações de diferentes culturas e organizações sociais distantes da sociedade envolvente.

$\mathrm{O}$ artigo "La formación de professores de matemáticas desde la etnomatemática: una mirada decolonial", de Hilbert Blanco-Alvarez e Edwin Molano-Franco, analisa criticamente as categorias transmodernidade, diálogo intercultural e analogia, relacionando-as à formação de professores de matemática. Elas são utilizadas para interpretações de propostas que envolvem a Etnomatemática, e são o mote para a apresentação de uma extensa revisão da literatura internacional sobre formação de professores em Etnomatemática. Os autores destacam que, tanto a formação inicial do professor de matemática, quando a continuada, poderiam envolver reflexões sobre o colonialismo da matemática ocidental, e que poderiam conscientizar estes educadores sobre a importância do estabelecimento de diálogos interculturais entre os diferentes saberes e atores da sociedade. Em seguida, apresentam uma experiência de formação de professores afrodescendentes em Tumaco-Colômbia, que teve a Etnomatemática como proposta política para a reinvidicação do estudo dos saberes da comunidade.

O artigo seguinte, de autoria de Éric Vandendriessche e Maria Cecilia Fantinato, apresenta um diálogo envolvendo análises sobre a etnomatemática no Brasil e na Europa, destacando as relações desse campo de pesquisa com a antropologia, a epistemologia e a educação. Sob o título "Ethnomathematique au Brésil et em Europe: un dialogue", os autores elencam pontos de suas 
trajetórias pessoais e acadêmicas, comentando a respeito das aproximações nas pesquisas envolvendo as relações entre etnomatemática e antropologia/etnografia. Neste e em outros pontos, destacam a colaboração de Ubiratan D’Ambrosio e de outros pesquisadores da área da etnomatemática que influenciaram os caminhos de suas pesquisas. Em seguida, apresentam reflexões a respeito de currículos que quando baseados em etnomatemática, permitiriam melhor compreender a complexidade do diálogo entre os diferentes saberes no contexto escolar. A parte final é destinada às análises a respeito dos atuais desafios para a etnomatemática como área de pesquisa.

Kécio Gonçalves Leite e Quesler Fagundes Camargos nos apresentam o artigo "Impossibilidades de mapeamentos bijetivos entre saberes matemáticos indígenas eurocêntricos". Partem da verificação da existência de saberes matemáticos originados e situados em diferentes contextos socioculturais. Destacam que, para os povos indígenas, o processo de colonização, foi bastante negativo, mas que a educação escolar indígena incorpora atualmente entre os seus princípios, o reconhecimento, a valorização e a promoção dos saberes de cada povo, assim como de suas línguas, identidades, histórias e culturas. Para isso, o recurso didático do bilinguismo tem despontado como uma possibilidade. Mas, por considerarem que as diferentes línguas se baseiam em sistemas de referência distintos e que as lógicas de diferentes saberes matemáticos não são equivalentes, este bilinguismo ainda tem gerado questões a serem superadas, tais como os problemas derivados da impossibilidade da utilização da simples tradução das ideias e palavras.

Fabio Lennon Marchon é o autor do artigo "O lugar da ficção na produção textual da Etnomatemática", e destaca que a obra assinada por Ubiratan D'Ambrosio abriu um novo caminho no interior da Educação Matemática, que foi o de dialogar com a literatura ficcional, com as produções cinematográficas, e com as novas mídias digitais. Dessa forma, o autor defende que o mundo do texto etnomatemático criado por D’Ambrosio seja encarado como um objeto literário. Analisa que boa parte destes textos são fruto de entrevistas, debates e palestras, ou seja, foi incialmente idealizado para a apresentação diante de uma plateia, com a intenção de convencê-la e persuadi-la em contextos específicos. Assim, o desafio era não apenas de informar algo, mas também de conquistar a adesão de um público para as ideias apresentadas. Além disso, tais textos envolvem a utilização de personagens diversos, além de um jogo de perguntas e respostas que servem também ao propósito de convencimento do público, e do leitor, das ideias etnomatemáticas.

O artigo seguinte, "Em fronteiras: a proposta do curriculum trivium no contexto de aulas de Português para haitianos" de Marília Prado e Cristiane Coppe de Oliveira, apresenta recorte de pesquisa que articula ideias do Programa Etnomatemática em um contexto educacional que envolve imigrantes, na cidade de São Paulo objetivando retirá-los das fronteiras da invisibilidade e do racismo. Destacam que, embora estes imigrantes haitianos atravessem as fronteiras de um país a outro, acabam 
permanecendo nas fronteiras culturais por dificuldades com o idioma, por exemplo. E nas fronteiras sociais, quando, por exemplo, exercem trabalhos precarizados. Em seguida, as autoras relatam alguns resultados da aplicação da metodologia de observação participante, e registros escritos em caderno de campo, tais como a possibilidade de aproximação do contexto de estudo destes imigrantes e o levantamento de elementos sobre a realidade deles no Brasil, a partir de relatos de suas experiências pessoais.

Filipe Santos Fernandes e Eliziara Pereira Coutinho nos apresentam o artigo "Decolonialidade, Educação do Campo e Formação de Professores de Matemática: por uma Reforma Agrária do Saber" que trata das relações entre a decolonialidade, a Educação do Campo e a formação de professores dentro de uma opção decolonial, visando novas possibilidades para a Universidade, de modo que nela aconteça o fenômeno de desobediência político-epistêmica. Os autores analisam que a inserção dos cursos de Educação do Campo nas Universidades tem provocado mudanças nas concepções e nas organizações do Ensino Superior, em especial, na formação de professores. Além disso, que a potência do pensamento etnomatemática auxilia na desconstrução das compreensões a respeito do conhecimento matemático, o que pode indicar novos caminhos para os processos formativos de professores da área da matemática, visto que passariam a envolver aspectos históricos, socioculturais e pedagógicos presentes em diferentes formas de vida, particularmente as camponesas.

O artigo de José Ricardo e Souza Mafra, intitulado "Um estudo de propriedades topológicas desenvolvidas na elaboração de incisos em superfícies curvas: uma leitura decolonial" apresenta um estudo realizado com artesãs, residentes na região do Aritapera, às margens do rio Amazonas. Na produção de cuias artesanais, estas mulheres obtêm formatos e dimensões diversificados, e para trabalharem em suas superfícies curvas, desenvolvem mecanismos instrumentais de marcação e escolha de referenciais, para a elaboração dos incisos. Dessa forma, as etapas de elaboração dessas cuias, envolvem diferentes manifestações de conhecimentos, mas não apenas aquelas relacionadas aos aspectos etnomatemáticos. Estas e outras percepções são analisadas pelo autor, tendo por base pressupostos etnomatemáticos e elementos teóricos pautados na decolonialidade, que significaria a defesa da necessidade de pensarmos soluções para o equilíbrio e permanência dessas práticas socioculturais.

A produção que fecha a parte dos artigos neste dossiê é intitulada "Os distanciamentos entre a Base Nacional Comum Curricular e a etnomatemática", de autoria de Adriano Vargas Freitas e Maria Cecilia Fantinato. Nela, é destacado um dos mais recentes documentos que influenciam diretamente as políticas educacionais em nosso país, incluindo a atualização de propostas curriculares das diferentes redes de ensino, a aprovação de livros didáticos a serem distribuídos às escolas públicas, e a formação dos professores, a Base Nacional Comum Curricular. Apresentado pelo 
governo federal e seus diversos apoiadores como definidor dos direitos de aprendizagens de todos os estudantes, nesta produção é destacado que a sua implementação envolveria a redução de currículos a simples objeto, a uma lista de conteúdos previamente dados, o que poderia ser configurado como um processo de colonização, padronização, controle, e invisibilização da diferença. Desta forma, ele se distancia de práticas curriculares alinhadas às perspectivas etnomatemáticas.

Este dossiê conta também com a rica apresentação de duas resenhas elaboradas pelos autores Andréa Thees, com o livro "O fim do império cognitivo: a afirmação das epistemologias do Sul” (de Boaventura de Souza Santos, 2019), e Thiago Donda Rodrigues, com o livro "Etnomatemática: concepções, dinâmicas e desafio" (de Maria Cecilia Fantinato e Adriano Vargas Freitas, 2018). Ambas as resenhas destacam as principais ideias das obras e suas formas metodológicas organizativas, convidando o leitor a folhear suas páginas e acompanhar importantes problematizações e reflexões que nelas são propostas. Em comum, a defesa do reconhecimento e valorização dos diferentes saberes, o que poderia ser um início de um importante e necessário movimento decolonial.

\section{Considerações finais e agradecimentos}

Como o crescimento da autoria acadêmica de representantes dos grupos sociais estudados e com o exercício da criticidade, a etnomatemática pode avançar no seu movimento decolonizador ${ }^{8}$. A etnomatemática pode contribuir para a sociologia das ausências, que "identifica as formas e os meios pelos quais a linha abissal produz a não existência, a invisibilidade radical e a irrelevância" (SANTOS, 2019, p.49), assim como para a sociologia das emergências, que "implica a valorização simbólica, analítica e política de formas de ser e de saberes que a sociologia das ausências revela estarem presentes no outro lado da linha abissal " (SANTOS, 2019, p.53). Este dossiê visa socializar produções de pesquisadores de etnomatemática brasileiros e estrangeiros, em busca do exercício de movimentos de resistência, adotando a perspectiva decolonial.

Por todas estas colaborações, temos muito a agradecer a cada um(a) dos(as) autores(as). Temos aqui neste dossiê perspectivas proveninentes de diferente contextos e lugares de fala, que levantam diversas questões atuais que alimentam o debate a respeito das relações entre a etnomatemática e a decolonialidade.

Outros agradecimentos especiais direcionamos aos editores da Revista de Educação Matemática (REMat), da Sociedade Brasileira de Educação Matemática (SBEM) - Regional São

\footnotetext{
${ }^{8}$ No contexto da educação indígena, isto acontece há mais de vinte anos. Recentemente, com o maior acesso de indígenas nas universidades, por conta das licenciaturas interculturais, vem crescendo lentamente a autoria indígena nos trabalhos acadêmicos em etnomatemática (Fantinato \& Leite, 2020).
} 
Paulo (SBEM-SP), não apenas pela calorosa acolhida ao nosso projeto, mas também pelo carinhoso acompanhamento de todo o processo editorial, em especial ao Prof. Dr. Rogério Marques Ribeiro.

\section{Referências}

ALMEIDA, S. R. G. Prefácio: apresentando Spivak. In G. Spivak (2010) Pode o subalterno falar? (p.7-18), Belo Horizonte, Brasil: Editora UFMG, 2010.

AKKARI, A.; DASEN, P. R. De l'éthnocentrisme de la pédagogie et ses remèdes. In: A. Akkari \& P. R. Dasen (eds) Pedagogies et pedagogues du Sud. Paris: 1’Harmattan, p.7-21, 2004.

BERNARLES, M.; POWELL, A. B. Decolonizing Ethnomathematics. Ensino Em-Revista 25(3) 565-587, 2018.

CAMPOS, M. D. SULear vs NORTEar: Representações e apropriações do espaço entre emoção, empiria e ideologia. Série Documenta, Programa de Mestrado e Doutorado em Psicossociologia de Comunidades e Ecologia Social (EICOS)/Cátedra UNESCO de Desenvolvimento Durável/UFRJ. Ano VI, n. 8, p. 41-70, 1999.

CLARETO, S. Conhecimento, Inventividade e experiência: Potências do pensamento Etnomatemático. In M. C. C. B. Fantinato (Ed.). Etnomatemática: novos desafios teóricos e pedagógicos. (p. 125-134). Niterói, Brasil: Editora da UFF, 2009.

CORONIL, C. Naturaleza del poscolonialismo: del eurocentrismo al globocentrismo. In Lander, E. (ed.) La colonialidad del saber: eurocentrismo y ciencias sociales. Perspectivas latinoamericanas. (p.83-107). Buenos Aires, Argentina: Clacso, 2000.

COSTA, W. N. G. Etnomatemática: uma tomada de posição da matemática frente à tensão que envolve o geral e o particular. In N. M. Gusmão (org.) Diversidade, cultura e educação: olhares cruzados. (p.201-223). São Paulo, Brasil: Biruta, 2003.

DUSSEL, E. europa, modernidad y eurocentrismo. In Lander, E. (ed.) La colonialidad del saber: eurocentrismo y ciencias sociales. Perspectivas latinoamericanas. (p.39-51). Buenos Aires: Clacso, 2000 .

D’AMBROSIO, U. Etnomatemática: Elo Entre as Tradições e a Modernidade. Belo Horizonte: Ed. Autêntica, 2001.

FANON, F. The Wretched of the Earth. Nova York: Grove, 1968.

FANTINATO, M.C.; LEITE, K. G. Ethnomathematics research on indigenous peoples knowledge and practices. In M. Rosa, \& C. Coppe (eds.) Ethnomathematics in Action: Mathematical Practices in Brazilian Indigenous, Urban and Afro Communities. Cham: Springer (in press), p.1-23, 2020. 
eISSN: $2526-9062$

FANTINATO. M. C; FREITAS, A. V.; DIAS, J. C. M. "Não olha para a cara da gente": ensino remoto na EJA e processos de invisibilização em contexto de pandemia. Revista Latinoamericana de Etnomatemática, 13(1), 104-124, 2020.

GROSFOGUEL, R. Para descolonizar os estudos de Economia Política e os estudos Pós-coloniais: transmodernidade, pensamento de fronteira e colonialidade global. In Santos, B. S. \& Meneses, M. P. (Eds.) Epistemologias do Sul. (pp. 383-417) Coimbra, Portugal: Edições Almedina, 2009.

LANDER, E. La colonialidad del saber: eurocentrismo y ciencias sociales. Perspectivas latinoamericanas. Buenos Aires: Clacso, 2000.

LANDRY, D.; MACLEAN, G. The Spivak reader. New Yok and London: Routledge.

MALDONATO-TORRES, N. On the Coloniality of Being: Contributions to the Development of a Concept. Cultural Studies, v.21, n.2-3, p.240-270, 2007.

MALDONATO-TORRES, N. Thinking through the decolonial turn: post-colonial interventions in theory, philosophy and critique - an introduction. Transmodernity: Journal of Peripheral Cultural Production of the Luso-Hispanic World, v.1, Issue 2, p.1-15, 2011.

POWELL, A. B.; FRANKENSTEIN, M. Ethnomathematics: Challenging Eurocentrism in Mathematics Education, Albany: State University of New York, 1997.

QUIJANO, A. Coloniality of Power, Eurocentrism and Latin American. Nepantla: Views from South 1(3) (pp. 533-580), 2000.

SANTOS, B. S. O fim do império cognitivo: a afirmação das epistemologias do Sul. Belo Horizonte: Autêntica Editora, 2019.

SPIVAK, G. Pode o subalterno falar? Belo Horizonte: Editora UFMG, p. 7-18, 2010. 